\title{
Reciclagem de resíduos secos domiciliares na cidade de São Paulo/SP e em outras cidades do mundo
}

Recycling of household dry waste in the city of São Paulo/SP and other cities of the world

Reciclaje de residuos secos domiciliares en la ciudad de São Paulo/SP y en otras

ciudades del mundo

Letícia Morais Neres

Discente, Universidade Nove de Julho - UNINOVE, Brasil.

leticianeresbio@gmail.com

Milena de Moura Régis

Professora Mestre, Universidade Nove de Julho - UNINOVE, Brasil. milenaregis@uni9.pro.br

Heidy Rodriguez Ramos Professora Doutora, Universidade Nove de Julho - UNINOVE, Brasil. 
RESUMO

A Cidade de São Paulo é a mais populosa do Brasil, e desde sua expansão industrial e social, é palco de impactos ambientais relacionados com o despejo de resíduos sólidos domiciliares, os quais se dão, pela falta de políticas públicas associadas a destinação adequada destes materiais. A reciclagem é uma alternativa viável e benéfica para a remediação do problema, pois, possibilita o reaproveitamento de resíduos que originalmente seriam despejados na natureza como rejeitos, bem como, a inclusão de cidadãos com baixa escolaridade e renda, no ciclo de geração de capital e estruturação social da Metrópole, além de consequentes efeitos positivos na economia. Neste contexto, o presente trabalho teve por objetivo investigar, por meio de pesquisa bibliográfica, o cenário da reciclagem de resíduos sólidos domiciliares na capital paulista, além de comparar os dados coletados com índices de outras cidades do mundo, visando compreender as diferenças e semelhanças dos sistemas implantados para pontuar, por fim, ações com potencial de aprimorar a inserção da reciclagem em São Paulo. A revisão da literatura demonstrou que os índices da reciclagem de resíduos na cidade de São Paulo apresentam grandes disparidades quando comparados a outras cidades no mundo. Desse modo, conclui-se que, ampliar a reciclagem, seguindo os exemplos de Berlim, Seattle e Tóquio, faria de São Paulo uma cidade mais sustentável, impulsionaria a economia da capital e promoveria qualidade de vida para a população em geral.

PALAVRAS-CHAVE: Reciclagem; Reciclagem de Resíduos Domiciliares; Sustentabilidade.

\section{ABSTRACT}

São Paulo is the most populous city in Brazil, and it has been, since its industrial and social expansion, a place filled with environmental impacts associated to the eviction of solid household waste, which became an issue mainly due to the lack of public policies related to the appropriate destination of these materials. In this context, recycling emerged as a viable and beneficial alternative to remediate this problem, as the activity provides the reuse of waste that would be originally thrown in nature as non-recyclable waste, as well as the inclusion of citizen with a low level of scholarship and income on the cycle of capital generation and social structure of the metropolis, in addition to the consequent positive effects on the economy. The present monograph had as its main objective to investigate, by researches in literatures pertinent to the studied topics, the scenario of solid household waste recycling in the Brazilian city, analyzing the amount of domestic waste that was sent to recycling, the structure of the management of the studied material, and also to compare the collected data with numbers of other cities in the world, aiming to understand the differences and similarities of the implanted systems to point, lastly, ways to potentially improve the insertion of recycling in São Paulo. The literature review has demonstrated that the rates of recycled waste in São Paulo present big disparities when compared to other cities in the world. That way, it has been concluded that expand the recycling activity following the examples of Berlin, Seattle and Tokyo would make São Paulo to become a more sustainable city, would boost the capital's economy and would promote quality of life to the population in general.

KEY-WORDS:Recycling; Household Waste Recycling; Sustainability.

\section{RESUMEN}

La ciudad de São Paulo es la más poblada de Brasil, y desde su expansión industrial y social, es escenario de impactos ambientales relacionados con el desalojo de residuos sólidos domiciliares, los cuales surgen por la falta de políticas públicas asociadas a la destinación adecuada de estos materiales. El reciclaje surgió como una alternativa viable y beneficiosa para la remediación del problema, pues, posibilita el reaprovechamiento de residuos que originalmente serían desechados en la naturaleza como desperdicios, así como la inclusión de ciudadano con baja escolaridad y renta en el ciclo de generación de capital y la estructuración social de la metrópoli, además de los consecuentes efectos positivos en la economía. En este contexto, el presente trabajo tiene como objetivo investigar por medio de un estudio bibliográfico, el escenario del reciclaje de residuos sólidos domiciliarios en la capital paulista, además de comparar los datos recolectados con índices de otras ciudades del mundo, paracomprender las diferencias y similitudes de los sistemas implantados y poder sugerir al final, acciones con potencial de mejorar la inserción del reciclaje en São Paulo. La revisión de la literatura demostró que los índices del reciclaje de residuos en la ciudad de São Paulo presentan grandes disparidades comparadas a otras ciudades del mundo. De este modo, se concluye que, ampliar el reciclaje siguiendo los ejemplos de Berlín, Seattle y Tokio, haría de São Paulo una ciudad más sostenible, impulsaría la economía de la capital y promovería calidad de vida para la población en general.

PALABRAS CLAVE: Reciclaje; Reciclaje de Residuos Domiciliarios; Sostenibilidad. 


\section{INTRODUÇÃO}

Apesar do termo "reciclagem" ser conhecido mundialmente, existem divergências na literatura quanto a real origem dessa atividade. Entretanto, Cavalcante e Tiujo (2013) observaram que a preocupação com o manuseio dos resíduos tornou-se relevante a partir da Revolução Industrial, em meados do século XVIII, que foi o grande marco de uma nova era na qual a dominação de novas tecnologias trouxe a produção em massa e consigo o consumismo, que por consequência começou a gerar impactos ambientais de diversas formas.

Associado a este fato, cabe ressaltar que na cidade de São Paulo a industrialização e a urbanização foram intensas e contínuas, visto que desde a década de 1930, a partir da cultura de cultivo do café, São Paulo começou a se destacar junto ao Rio de Janeiro como centro industrial do país (CANO, 1988). A partir dos anos 1970, o Município de São Paulo começa a se consolidar como metrópole, em consequência da nivelação social na Cidade, que passou a ficar mais explícita ao passo que o crescimento populacional acelerava (CANO; SEMEGHINI, 1992). Cano e Semeghini (1992) salientaram que as consequências da negligência na organização da formação infraestrutural urbana da cidade passaram a ficar mais evidentes a medida que São Paulo crescia, gerando os problemas visíveis e abrangentes não somente no âmbito natural, mas também em aspectos sociais. Desse modo, o aumento da poluição passou a ser propriamente notável e os impactos ambientais foram claramente frutos da falta de zelo com a natureza.

O consumo exorbitante e a omissão de uma gestão de resíduos eficiente já causaram e têm causado cada vez mais impactos sobre a natureza de forma irreversível (GODECKE et al.,2012). Nesse sentido, Franco (2008) também interligou o descaso com o planejamento sustentável das cidades com os padrões de vida impostos na sociedade, e expõe a ideia de que a plenitude que o homem procura está no consumismo material irresponsável e, por vezes, sem critérios. Nalini (2008) explicou que a geração de resíduos domiciliares, por exemplo, é há muitos anos um grande desafio para São Paulo. $O$ autor também destacou que o município possui números alarmantes no que diz respeito aos índices de crescimento da utilização de embalagens ao longo de sua história, os quais, em sua maioria, são materiais passíveis a processos de reciclagem.

De acordo com dados da Prefeitura da Cidade de São Paulo, até o início de 2013 eram reciclados somente $1,74 \%$ de um total de 12,5 mil toneladas de resíduos domiciliares produzidos por dia (PPSP, 2016). Estatísticas mais recentes divulgadas pelo governo da Inglaterra mostram que entre 2016 e 2017, só na cidade de Londres, 33\% de todo o lixo domiciliar coletado é reciclado e esse é o índice de reciclagem mais baixo do país britânico (DEFRA, 2017). Tais informações demonstram que há um grande contraste na administração do gerenciamento de resíduos entre Londres e São Paulo.

Nesse sentido, Juras (2012) descreveu que mesmo que a Política Nacional de Resíduos Sólidos (PNRS) tenha representado um passo importante para uma cultura mais sustentável, as leis ambientais brasileiras em sua maioria ainda são defasadas, refletindo diretamente nos baixos números observados em diversos âmbitos, entre eles o da reciclagem. A autora também apresentou as características das políticas públicas voltadas ao meio ambiente em outros 
países, as quais muitas servem de exemplo de eficiência e responsabilidade para com o meio ambiente.

Sendo assim, a reciclagem é uma alternativa muito importante e viável, a qual engloba todas as camadas da sociedade, pois o reaproveitamento de materiais gera não somente benefícios ambientais grandiosos, mas também a geração de empregos, principalmente para a população de baixa renda, além de impactar positivamente na economia, visto que o desperdício se torna potencialmente reversível (REIS et al., 2015). Tais aspectos justificam o desenvolvimento desse estudo, que teve por objetivo investigar o cenário atual da reciclagem de resíduos secos domiciliares na Cidade de São Paulo/SP e em outras cidades do mundo.

\section{METODOLOGIA}

\section{1.COLETA DE DADOS}

Para o desenvolvimento deste trabalho foi realizada uma pesquisa bibliográfica nas bases de dados: Google Acadêmico e Scielo, cruzando as palavras-chave: "Impactos Ambientais"; "Reciclagem"; "Reciclagem de Resíduos Domiciliares" e "Sustentabilidade", para levantar os especialistas que estudam o cenário da reciclagem de resíduos domiciliares na Cidade de São Paulo e em outras cidades do mundo, considerando o período de tempo de 1988 a 2018.

\section{MÉTODO DE ANÁLISE}

Os artigos levantados nas bases de dados Google Acadêmico e Scielo, foram cuidadosamente analisados para verificar a adequação com o objetivo levantado nesse trabalho. Os dados foram tabulados considerando o ano de publicação do trabalho, o local (cidade, estado e região) no qual o estudo foi realizado; os principais conceitos teóricos; informações sobre a importância e aspectos positivos e negativos da Reciclagem dos Resíduos Domiciliares, além das conclusões e principais observações dos autores levantados.

\section{RESULTADOS}

\section{1. A CLASSIFICAÇÃO DE RESÍDUOS E O CONCEITO DE RECICLAGEM NO BRASIL}

A Fundação Nacional de Saúde (FUNASA) destaca que os resíduos sólidos são provenientes de todas as etapas do ciclo de um material, desde a matéria-prima até o produto final. Desta forma, cabe frisar a diversidade dos meios geradores e consequentes diferenças de composição dos resíduos, tornando imprescindível a organização dos mesmos de acordo com sua origem e periculosidade para, desta forma, adequar técnicas de manejo que mitigam a degradação ambiental (FUNASA, 2014).

Garciaet al. (2015) caracterizaram a definição de resíduos sólidos como materiais cuja vida útil para utilização em atividades antrópicas se esgota. Além disso, os autores também relacionam o termo com "lixo", contextualizando em uma perspectiva mais atual a administração dos resíduos produzidos pela população e introduzindo a realidade do lixo na vida cotidiana da 
sociedade, de forma a demonstrar a importância do gerenciamento correto do ciclo dos resíduos sólidos.

A legislação brasileira norteia a classificação de resíduos a partir de dois princípios básicos: origem e periculosidade. Na designação quanto a origem, são organizadas as terminologias dos diferentes tipos de resíduos quanto sua fonte geradora. Quanto a periculosidade, são classificados os resíduos específicos de acordo com o seu potencial de gerar ou não perigo (BRASIL, 2010).

No Japão, por exemplo, os resíduos são divididos entre os que são produzidos pela população local e os que são gerados por indústrias. Com base nesses preceitos, foram criadas subdivisões diversas para os diferentes tipos de características do lixo. Visando, assim como observado também nas normativas do Brasil, estabelecer uma organização específica para cada tipo de resíduo a fim de obter controle sobre o ciclo de cada material na natureza (ME, 2018).

A lei $12.305 / 10$, de 2 de agosto de 2010, descreve a reciclagem, na definição XVI de seu 3o artigo, como um:

[...] processo de transformação dos resíduos sólidos que envolve a alteração de suas propriedades físicas, físico-químicas ou biológicas, com vistas à transformação em insumos ou novos produtos, observadas as condições e os padrões estabelecidos pelos órgãos competentes do SISNAMA (Sistema Nacional do Meio Ambiente) e, se couber, do SNVS (Sistema Nacional de Vigilância Sanitária) e do SUASA (Sistema Unificado de Atenção à Sanidade Agropecuária) (BRASIL, 2010).

Teixeira e Bidone (1999) destacaram a reciclagem como forma de gestão dos resíduos e a definem com base nos processos que fazem com que os resíduos passem a ser considerados novamente matéria-prima.

\subsection{DEFINIÇÃO DA RECICLAGEM DE RESÍDUOS DOMICILIARES E A PROBLEMÁTICA ENVOLVIDA EM SÃO PAULO}

A prefeitura de São Paulo define resíduo domiciliar como:

[...] aquele originado da vida diária das residências, constituído por setores de alimentos (tais como: cascas de frutas, verduras, dentre outros), produtos deteriorados, jornais e revistas, garrafas, embalagens em geral, papel higiênico, fraldas descartáveis e uma grande diversidade de outros itens, bem como, alguns resíduos que podem ser tóxicos(PPSP, 2009).

Dentro dos resíduos sólidos domiciliares, cabe destacar os resíduos orgânicos, os quais representam mais da metade do volume de resíduos sólidos gerados em todo o Brasil. Neste contexto, entra a compostagem que se trata de uma via de reaproveitamento desse tipo de resíduo, transformando o em adubo ou fertilizante orgânico (MMA, 2018a).

A urbanização, industrialização e consumismo desenfreados estão intimamente interligados e em São Paulo a combinação destas atividades geraram, e ainda geram, impactos socioambientais extremamente relevantes, por conta dos resíduos gerados em grande quantidade, os quais, desprovidos de controle de produção e descarte sustentável, ameaçam o meio-ambiente de forma preocupante diante de seu alto grau poluente, conforme explicaram Jacobi e Bensen (2006). 
A negligência do governo quanto ao compromisso com a criação de novos centros de triagem, a ineficiência dos espaços de trabalho para a segregação do material reciclável e a falta de receptividade do povo paulistano, quanto a sua responsabilidade voluntária de colaboração, fizeram o Município de São Paulo atingir números baixos e alarmantes no que diz respeito a reciclagem de resíduos e destinação inadequada destes. Assim, causando diversos impactos ao meio ambiente e afetando negativamente a economia, fazendo com que a coleta seletiva se tornasse um forte instrumento comercial do setor privado (JACOBI; BENSEN, 2011).

A problemática da administração de resíduos em São Paulo é extensa e se espalha por diversas vertentes. Grande parte da ineficácia e das consequentes degradações ambientais, enfrentadas na cidade por conta dos resíduos, se dá por uma estrutura falha das políticas públicas associadas e dos setores econômicos e sociais relacionados, causada pela negligência dos órgãos e autoridades responsáveis, da própria população paulistana que não possui uma cultura de vida sustentável e pela corrupção, que atinge os investimentos necessários para criar o suporte que uma cidade como São Paulo necessita para que todos os resíduos domiciliares gerados sejam tratados de forma adequada (GONÇALVES et al., 2013).

As estratégias para o melhor manejo dos resíduos sólidos domiciliares presentes no Plano de Gestão Integrada de Resíduos Sólidos (PGIRS) de 2014 foram traçadas a curto, médio e longo prazo, priorizando uma organização socioeconômica em que a população da Cidade de São Paulo e os catadores passassem a ter uma participação maior no ciclo das embalagens recicláveis, fortalecendo a coleta seletiva e evitando o despejo irregular desses materiais em aterros sanitários, os quais, ainda segundo o documento, eram até a data de publicação do mesmo, o destino da maior parte desses resíduos. O PGIRS ainda destaca a responsabilidade do setor privado e do poder público de se adequarem às normativas propostas, enfatizando ainda mais a importância da ação conjunta da sociedade para a remediação destes problemas (PMSP, 2014).

É importante ressaltar, conforme observou Banerjee (2015), que reciclagem é uma alternativa necessária de gestão de resíduos em geral, pois o reaproveitamento do lixo gera muitas vantagens para o meio ambiente e a sociedade. Mas, salientou o autor, não deve ser vista como a solução definitiva para a problemática dos resíduos, visto que sua função é mais voltada para atrasar a escassez de recursos não renováveis, do que para garantir que a uma cultura sustentável forte se estabeleça por meio de uma economia cuja base sejam os recursos renováveis.

\subsection{CENÁRIO DA RECICLAGEM DE RESÍDUOS DOMICILIARES EM SÃO PAULO E EM OUTRAS CIDADES DO MUNDO}

Na Cidade de São Paulo a coleta dos resíduos domiciliares funciona desde 2002 por meio de regime de concessão, as principais metas traçadas foram baseadas na logística de tratamento do resíduo orgânico e no reaproveitamento dos materiais sólidos, os recicláveis. Cabe mencionar que, a coleta seletiva no Município conta com a colaboração da população carente, que encontrou nos resíduos uma fonte de renda e de subsistência - são os chamados "catadores" e da população que destina os resíduos recicláveis a centros de coleta (JACOBI; BENSEN, 2011).

Neste contexto, o Ministério do Meio Ambiente (MMA) destaca a coleta seletiva como uma alternativa útil e necessária para a gestão sustentável dos resíduos domiciliar passíveis de reciclagem. $O$ processo de coleta seletiva consiste na organização dos resíduos de acordo com sua composição e constituição, para que sejam reinseridos no ciclo de produção (MMA, 2018b). 
O cenário apresentado pela Prefeitura de São Paulo por meio do PGIRS em 2014 mostrou que a média de geração de resíduos domiciliares per capita na cidade é de 1,1kg por habitante por dia, e $35 \%$ de todo o resíduo gerado nas residências é passível de reciclagem. Ainda segundo o PGIRS, os resíduos sólidos domiciliares coletados por caminhões de lixo convencionais são levados a estações de transbordo, que são pontos intermediários nos quais são concentrados os resíduos coletados pelos caminhões, para posterior evacuação para os aterros sanitários cujos dois principais espaços estão localizados no bairro de São Mateus (na Cidade de São Paulo) e no Município de Caieiras/SP (PMSP, 2014).

Conforme mencionado anteriormente, os índices apresentados pela Prefeitura da Cidade de São Paulo apontam que até o início de 2013 eram reciclados 1,74\% de um total de 12,5 mil toneladas de resíduos domiciliares (PPSP, 2016). Enquanto um levantamento feito pela União Europeia, em 2015, comprovou que a cidade de Berlim, capital da Alemanha, desde 2008 recicla cerca de $80 \%$ dos resíduos domiciliares gerados na cidade (EU, 2015), conforme apresentado no quadro 1.

Paschoalin et al. (2014) salientou as maléficas consequências dos baixos índices de reciclagem na Cidade de São Paulo e da prioridade do Poder Público em transferir o lixo doméstico para aterros, administrando a logística de materiais que têm potencial de reaproveitamento como se estes fossem rejeitos, posto que o adiamento de um gerenciamento voltado para o reaproveitamento e até mesmo falta da disposição segura e ambientalmente saudável dos resíduos, gera um grande desperdício monetário. Além de um custo ainda mais alto para a natureza, com os impactos e degradações causados.

Por outro lado, a Alemanha pode ser considerada um país modelo no que diz respeito ao manejo dos resíduos sólidos, pois construiu em sua legislação federal uma estrutura de distribuição de responsabilidade no ciclo dos materiais recicláveis, visando e exigindo desde os fabricantes de quaisquer embalagens até o consumidor destas o compromisso de priorizar a recuperação desses resíduos se esta for a opção mais viável e mais benéfica para o meio ambiente. Além de ordenar que, em todo o território nacional alemão, a disposição de resíduos seja somente realizada em espaços autorizados, dando enfoque na fiscalização e monitoramento no cumprimento das normativas impostas para sua população (JURAS, 2012).

Em contrapartida, a Bolívia é um país extremamente ultrapassado no que diz respeito ao manejo de resíduos domiciliares, visto que o país Sul-Americano não possui sequer leis específicas para a estruturação do mesmo. Nesse país a organização da coleta de resíduo domiciliar é feita de forma independente pelos municípios, apenas materiais com alto grau tóxico, como baterias e materiais eletrônicos, são descartados de forma adequada, mas a destinação do material doméstico coletado contendo principalmente papel, plástico, metais, vidros e matéria orgânica é feita em sua maior parte em lixões. Os índices de reciclagem no país ainda estão muito aquém do ideal, apesar de terem apresentado aumento relevante desde 2010 (METASUS, 2015), conforme quadro 1.

Kadafa (2017) expõe as dificuldades da gestão de resíduos domiciliares em Abuja, capital da Nigéria, por meio de pesquisas de campo, com foco na população da cidade nigeriana, o autor constatou que a maior parte dos cidadãos utilizam técnicas de destinação do resíduo com alto potencial impactante, como: a queima; o aterramento independente no solo - sem fiscalização; e deposição em lixões em bairros vizinhos; pois, grande parte das pessoas não tem a seu dispor a coleta dos resíduos de forma regular. Segundo o autor, o índice de reciclagem é de $17 \%$, (quadro 1 ) e pode ser explicado pelo valor econômico dos materiais recicláveis que a própria população procura reutilizar, diante da baixa renda per capita que impede um consumismo recorrente de certos materiais. 
A cidade de Seattle, nos Estados Unidos, aumentou em 33,6\% a quantidade de resíduos domiciliares reciclados entre os anos 2000 a 2016, segundo dados da (Seattle Public Utilities [SPU], 2016). A meta é aumentar até 2020 mais 17,1\% na quantidade de resíduos domésticos reciclados, atingindo $75 \%$ no total (quadro 1), e desta forma, alcançar metas traçadas pelo Plano Municipal de Gerenciamento de Resíduos (PMGR), criado em 1997 (SPU, 2016). O aumento da quantidade de resíduos reciclados, nos últimos dezoito anos, deve-se a projetos de educação ambiental, realizados em casas e escolas, bem como a ações governamentais as quais disponibilizaram recipientes separadores, gratuitamente, para moradores, em pontos próximos das residências e prédios do município (SPU, 2016).

No Brasil, a PNRS representa uma evolução importante para a fomentação de uma administração eficiente dos resíduos. Mas, no País, ainda são observadas políticas públicas ultrapassadas vigorando, estas normativas destoam da realidade dos impactos ambientais causados pelo descarte inadequado de resíduos domiciliares na natureza (JURAS, 2012).

Por outro lado, Tóquio, no Japão, possui uma forte cultura de prevenção de geração de resíduos, mas o gerenciamento do lixo é feito utilizando principalmente o método de incineração. Entretanto, a capital japonesa dispõe de técnicas para reciclar os rejeitos oriundos da própria incineração, por meio de reações químicas em estruturas que recebem gases poluentes, com o potencial de estabilizar e decompor os compostos formados no processo (quadro 1), conseguindo desta forma mitigar os impactos causados no meio ambiente por conta dessa atividade (TEPSC, 2018). 
Quadro 1. Cenário da reciclagem de resíduos secos domiciliares no Brasil e no Mundo, segundo os autores estudados neste trabalho.

\begin{tabular}{|l|c|l|}
\hline \multicolumn{1}{|c|}{ Autores } & Países & \multicolumn{1}{|c|}{ Cenário da Reciclagem de Resíduos Domiciliares } \\
\hline $\begin{array}{l}\text { Prefeitura da Cidade de São } \\
\text { Paulo (PPSP, 2016). }\end{array}$ & Brasil & $\begin{array}{l}\text { De } 12,5 \text { mil toneladas de resíduos sólidos domiciliares } \\
\text { produzidas diariamente na cidade de São Paulo, apenas } \\
1,74 \% \text { é reciclado. }\end{array}$ \\
\hline União Europeia (UE, 2015). & Alemanha & $\begin{array}{l}\text { A cidade de Berlim recicla cerca de } 80 \% \text { do resíduo } \\
\text { domiciliar produzido na cidade. }\end{array}$ \\
\hline $\begin{array}{l}\text { Europena Sustainable Solutions } \\
\text { (METASUS, 2015). }\end{array}$ & Bolívia & $\begin{array}{l}\text { A reciclagem na Bolívia se dá de forma independente, por } \\
\text { seus cidadãos, por conta deste fato, os índices de } \\
\text { reciclagem subiram nos últimos anos. }\end{array}$ \\
\hline Kadafa (2017). & Nigéria & $\begin{array}{l}\text { A cidade de Abuja recicla cerca de 17\% dos resíduos } \\
\text { produzidos. }\end{array}$ \\
\hline $\begin{array}{l}\text { Seattle Public Utilities (SPU } \\
\text { 2016). }\end{array}$ & Seattle & $\begin{array}{l}\text { A cidade de Seattle, nos Estados Unidos, reciclou em 2016 } \\
\text { por volta de 63,9\% dos resíduos domiciliares, e até 2020 } \\
\text { pretende aumentar essa estimativa a 75\%. }\end{array}$ \\
\hline $\begin{array}{l}\text { Tokyo Environmental Public } \\
\text { Service Corporation (TEPSC, } \\
\text { 2018). }\end{array}$ & Japão & $\begin{array}{l}\text { A cidade de Tóquio possui uma política de prevenção de } \\
\text { criação de resíduos muito forte. Além disso, reciclados } \\
\text { subprodutos do processo de incineração. }\end{array}$ \\
\hline
\end{tabular}

FONTE: Elaborado pelas autoras (2019)

Gutberlet (2011) explicou que a incineração tem o potencial de reduzir em grande escala a massa de resíduos e desta forma diminuir a necessidade da construção de aterros sanitários para a disposição do lixo. Mas os rejeitos tóxicos, provenientes da queima dos resíduos, poluem de forma agressiva o meio-ambiente, tornando este processo altamente impactante. A autora destacou que a reciclagem é uma alternativa mais sustentável, mais saudável economicamente e mais socialmente benéfica, sobretudo para os catadores, enquanto a incineração possui um custo exorbitante e não gera tantas possibilidades de emprego e lucro como a reciclagem. Por fim, no Brasil a PNRS definiu metas e impôs, seguindo o exemplo de outras nações, a responsabilidade compartilhada sobre o ciclo dos resíduos, buscando incluir a participação de todos os cidadãos e a valorização do trabalho dos catadores (TEODÓSIO et al., 2016).

\subsection{SUSTENTABILIDADE POR MEIO DA RECICLAGEM DE RESÍDUOS SECOS DOMICILIARES}

A reciclagem dos resíduos secos domiciliares traz muito mais vantagens para a natureza do que o aterramento do lixo, ainda que os aterros sanitários disponham de estrutura e dispositivos para que as substâncias provenientes da decomposição não afetem o meio ambiente, como explicaram Ruberg et al. (2000). Neste contexto, os autores também destacaram que os principais materiais recicláveis, encontrados nos resíduos domésticos (papel, vidro, plástico e metal), possuem o potencial de serem reaproveitados, minimizando consideravelmente os impactos ambientais em diversas vertentes.

Souza e Mello (2015) apontaram que, do ponto de vista social e econômico, reciclar resíduos secos domiciliares é uma atividade muito benéfica e eficiente. De acordo com as autoras, os "catadores" são, na grande maioria das vezes, pessoas com poderio financeiro extremamente baixo e que encontraram no difícil trabalho de segregação dos resíduos, para encontrar materiais com valor econômico e que possam ser comercializados em depósitos de sucata, um meio de sobrevivência. Além disso, indiretamente, a mão de obra barata e marginalizada 
desses trabalhadores informais reflete positivamente na economia federal, visto que a quantidade de resíduos reciclados aumenta consideravelmente, no entanto, o trabalho dessas pessoas ainda é pouco reconhecido e estes continuam sendo alvo de preconceito e discriminação (SOUZA; MELLO, 2015).

Reconhecer a relevância da reciclagem e a participação de cada indivíduo nesse processo é essencial, pois as etapas de estruturação da população humana, a rotina nas cidades e a exploração dos recursos naturais de forma desenfreada, influenciaram diretamente na degradação rápida e em massa do Planeta Terra, motivando à necessidade de medidas urgentes de remediação (SILVA et al., 2015).

O Roteiro para Fechamento de Lixões, publicado pela Associação Brasileira de Empresas de Limpeza Pública e Resíduos Especiais (ABRELPE), explicita a necessidade emergencial de se voltar esforços para a preservação ambiental por meio do manejo de resíduos, dado que diversas áreas da sociedade estão englobadas neste processo e dependem do mesmo para que a vida seja preservada. O documento denomina, portanto, a gestão correta e eficiente de resíduos sólidos como um direito humano básico, diante de todos os impactos e consequências que o lixo gera na vida da população, e consequentemente, do planeta em si (ABRELPE, 2017).

Cabe ressaltar que, os conceitos da reciclagem precisam ser ajustados, uma vez que a introdução e a execução desse sistema são baseadas em interesses econômicos e de órgãos governamentais. No entanto, o poder público, infelizmente, não apoia programas de reciclagem de resíduos e, consequentemente, não dá o suporte financeiro, social e cultural necessários para a efetividade plena da reciclagem, assim acarretando na desvalorização do trabalho de catadores e dos benefícios da reciclagem para a sociedade (LEAL et al., 2015).

\subsection{RELAÇÃO DA PRESERVAÇÃO AMBIENTAL COM A RECICLAGEM DE RESídUOS SECOS DOMICILIARES}

Lira et al. (2016) explicaram que a utilização de aterros sanitários como destinação final de resíduos é uma alternativa que se encaixa com a realidade atual da gestão ambiental no Brasil, mas ressaltaram que os impactos ambientais causados pela instalação dos aterros e os subprodutos provenientes do lixo no solo, água ou ar, são extremamente relevantes e implicam em degradações ecossistêmicas graves.

A Prefeitura de São Paulo afirma que não existem lixões operando na capital (PPSP, 2018). Entretanto, a Companhia Ambiental do Estado de São Paulo (CETESB), por meio do Inventário Estadual de Resíduos Sólidos Urbanos de 2017, apontou que até o ano de publicação da minuta, 3,9\% dos municípios do estado paulista ainda possuem lixões em operação, totalizando 25 cidades. O documento menciona que de 2013 a 2015 houve um aumento nos índices, de 4,5\% para 6,4\%, mas com diminuição dos números nos anos seguintes.

Tais aspectos demonstram a importância do processo de reciclagem, pois este transforma os resíduos em matéria-prima basal, para a fabricação de um outro produto, gerando: economia de recursos naturais - os quais muitos não são renováveis; menor demanda da produção em massa de produtos e dos processos de industrialização relacionados; assim, minimizando significativamente a emissão de poluentes na atmosfera, solo e água. A transformação dos resíduos em insumo novamente diminui a disposição final em aterros, prolongando a vida útil dos mesmos e por consequência extinguindo a necessidade da criação destes e de lixões clandestinos. Desta forma, beneficiando a conservação da fauna e flora que seriam desmatados e dos demais recursos naturais (DONATO et al., 2015). 
É pertinente observar, de acordo com Waldman (2015), que por mais que a reciclagem em si possua um enorme potencial de preservar a natureza, é necessário também levar em conta os conceitos de reduzir e reutilizar, de forma dinâmica com o método reciclador, formando, portanto, os chamados três " $R$ 's". O autor advertiu que ao se analisar o cenário atual de consumo e descarte de materiais, não é possível destinar toda a quantidade de resíduo produzido para a reciclagem e desta forma, expõe as limitações desta atividade no âmbito da mitigação de impactos ambientais. Salientando que a melhor maneira de minimizar as degradações causadas pelos resíduos é reduzir o consumo e, consequentemente, reduzir a inevitabilidade do descarte.

\section{CONCLUSÃO}

Os dados obtidos, a partir da revisão literária, permitem concluir que os índices da reciclagem de resíduos secos domiciliares na Cidade de São Paulo apresentam grandes disparidades quando relacionados a quantidade dos resíduos criados no Município. Este fato se dá pela falta de adesão do Poder Público as políticas associadas com a destinação destes resíduos, os quais, em sua grande maioria, são eliminados de maneiras muito nocivas ao meio ambiente quando despejados em aterros sanitários, terrenos baldios ou até mesmo permanecem nas ruas, em locais em que o serviço de limpeza pública não funciona ou não é eficiente o suficiente para a demanda de resíduos gerados.

Associado a este fato estão os catadores, que ao longo dos anos permanecem sem ter seu trabalho valorizado, construindo uma renda muito baixa e exercendo seus serviços em condições insalubres, colocando sua saúde em risco, mesmo com políticas trabalhistas voltadas para estes profissionais, mas que não abrangem de forma eficaz as diretrizes para oferecer o ambiente de trabalho que essas pessoas realmente merecem e precisam.

Existem desafios educacionais, morais e éticas na questão da baixa reciclagem dos resíduos secos domiciliares no Município de São Paulo, visto que a maioria da população paulista não separa seus resíduos por falta de hábito. Isso está associado com a falta de informação sobre as etapas de manejo dos resíduos doméstico de forma adequada para contribuir com a coleta seletiva, e também com a falta de consciência da responsabilidade de cada cidadão em exercer este papel, uma vez que a segregação dos resíduos não é uma prioridade para a maioria das pessoas, que ignoram sua própria participação na construção de uma cidade mais sustentável. A educação ambiental, atualmente, está sendo mais explorada no âmbito escolar, principalmente no trabalho com crianças é de suma importância oferecer na educação infantil informações práticas sobre o papel de cada indivíduo na preservação ambiental, em razão da enorme influência que a educação escolar promove sobre as crianças, no sentido da construção da consciência cívica e ética, perante a sociedade e a natureza.

Cabe ressaltar que as políticas ambientais brasileiras, associadas com a administração dos resíduos, passaram por reformas importantes e positivas. Em outros países, como a Nigéria e a Bolívia, que são nações muito pobres, sequer existem normativas para a gestão dos resíduos em suas capitais, e ainda se fazem necessárias leis que estruturem a coleta de lixo em si.

Por outro lado, é relevante observar que nações com maior grau de desenvolvimento, como Alemanha, Estados Unidos e Japão, estão em um estágio muito mais avançado em relação ao gerenciamento de seus resíduos. Os índices observados em Seattle e em Berlim comprovam que é fundamental o investimento do Poder Público em educação ambiental e espaços de reciclagem que sejam compostos por trabalhadores, para a correta segregação do material e seu posterior reaproveitamento. O Japão possui um nível de conscientização ambiental muito 
alto, visto que o país asiático conseguiu chegar no ponto de impor a prevenção de criação de resíduos em Tóquio e a medida funciona.

Desse modo, a prevenção de criação dos resíduos, a ponto de minimizá-los o máximo possível, se faz a medida mais adequada. Entretanto, a reciclagem é uma ferramenta muito importante para a construção de uma cidade mais sustentável e ambientalmente correta, uma vez que possibilita a inserção dos materiais no meio de produção novamente em forma de matériaprima, reduzindo em quantidades altas gastos e impactos ambientais, além de servir como instrumento de inserção social de classes sociais menosprezadas na sociedade.

Neste sentido, a Cidade de São Paulo precisa que esta atividade possua maior inserção e abrangência de forma organizada e fiscalizada. É essencial a existência de políticas públicas especificas e que englobam o tripé da sustentabilidade de maneira séria e consistente na capital paulista, promovendo a reciclagem dos resíduos secos domiciliares, dada a magnitude do Município de São Paulo, com relação ao número de habitantes e a quantidade de resíduos gerados que poderiam ser reaproveitados, mas são descartados desnecessariamente.

Sendo assim, o crescimento da inclusão da reciclagem de resíduos secos domiciliares, seguindo os exemplos de Berlim, Seattle e Tóquio, não só faria de São Paulo uma Cidade mais sustentável, como também impulsionaria a economia da capital e serviria de ferramenta para uma maior justiça social, possibilitando uma vida mais digna para àqueles que carecem de necessidades básicas e promovendo qualidade de vida para a população em geral.

\section{REFERÊNCIAS}

ABRELPE - Associação Brasileira de Empresas de Limpeza Pública e Resíduos Especiais. Roteiro para Encerramento de Lixões - Os lugares mais poluídos do mundo. 2017. Disponível em

(http://www.abrelpe.org.br/Panorama/iswa_web3.pdf). Visualizado em 14/08/2018.

BANERJEE, R. Importance of Recycling. International Journal of Innovative Research in Electrical, Electronics, Instrumentation and Control Engineering. 3:53-55, 2015.

BRASIL. Lei 12.305, de 2 de agosto de 2010. Institui a Política Nacional de Resíduos Sólidos; altera a Lei no 9.605, de 12 de fevereiro de 1998; e dá outras providências. Diário Oficial (da República Federativa do Brasil), Brasília, 2010.

CANO, W. Questão regional e urbanização no desenvolvimento econômico brasileiro pós 1930. In: Encontro Nacional de Estudos Populacionais, 6, Olinda, 16 a 20 de out. 1988. Anais do VI ENCONTRO NACIONAL DE ESTUDOS POPULACIONAIS. Olinda: ABEP, 2, p. 67-99, 1988.

CANO, W.; SEMEGHINI, U. C. Urbanização, crise social e o papel das entidades regionais em São Paulo. In: Encontro Nacional de Estudos Populacionais, 8, São Paulo, 1992. Anais do VIII ENCONTRO NACIONAL DE ESTUDOS POPULACIONAIS. São Paulo: ABEP, 3, p. 271-283, 1992.

CAVALCANTE, Z. V.; TIUJO, E. M. Poluição: Origem histórica e reciclagem In: VI Mostra Interna de Trabalhos de Iniciação Científica, 6, Maringá, 23 a 26 out. 2012. Anais da VI Mostra Interna de Trabalhos de Iniciação Científica.Maringá: Unicesumar, 2012.

DEFRA - Department for Environment Food \& Rural Affairs. National Statistics. Statistics on waste managed by local authorities in England in 2016/17.2017. Disponivel em

(https://www.gov.uk/government/uploads/system/uploads/attachment_data/file/664594/LACW_mgt_annual_Stat s_Notice_Dec_2017.pdf). Visualizado em 10/03/2018.

DONATO, L. A., BARBOSA, M. F. N., BARBOSA, E. M. Reciclagem: o caminho para o desenvolvimento sustentável. Polêm!ca. Rio de Janeiro, 15, 2:23-34, 2015. 
EU - European Union. DE Berlin Capital Factsheet. 2015. Disponível em

(https://www.municipalwasteeurope.eu/sites/default/files/DE\%20Berlin\%20Capital\%20factsheet.pdf).Visualizado em 28/04/2018.

FRANCO, M. A. R. Planejamento ambiental para a cidade sustentável. 2 ed. São Paulo: Annablume, 2008. 253 p.

FUNASA - Fundação Nacional de Saúde. Manual de orientações técnicas para elaboração de propostas para o programa de resíduos sólidos. 2014. Disponível em

(http://www.funasa.gov.br/documents/20182/34981/manualdeorientacoestecnicasparaelaboracaodepropostasresi duossolidos.pdf/d84790e5-647b-47c6-b393-bfd89a322563). Visualizado em 15/05/2018.

GARCIA, M. B. S.; NETO, J. L.; MENDES, J. G.; XERFAN, F. M. F.; VASCONCELLOS, C. A. B.; FRIEDE, R. R. Resíduos sólidos: responsabilidade compartilhada. Revista Científica Semioses. 9, 2:77- 91, 2015.

GODECKE, M. V.; NAIME, R. H.; FIGUEIREDO, J. A. S. O consumismo e a geração de resíduos sólidos urbanos no Brasil. REGET - Revista Eletrônica em Gestão, Educação e Tecnologia Ambiental. 8, 8:1700-1712, 2012.

GONÇALVES, M. A.; TANAKA, A. K.; AMEDOMAR, A. A. A destinação final dos resíduos sólidos urbanos: alternativas para a cidade de São Paulo através de casos de sucesso. Future StudiesResearchJournal: TrendsandStrategy. 5, 1:96-131, 2013.

GUTBERLET, J. O custo social da incineração de resíduos sólidos: recuperação de energia em detrimento da sustentabilidade. Revista Geográfica de América Central, 2:1-16, 2011.

JACOBI, P. R.; BESEN, G. R. Gestão de resíduos sólidos em São Paulo: desafios da sustentabilidade. Estudos avançados. 25, 71:135-158, 2011.

JACOBI, P. R.; BESEN, G. R. Gestão de resíduos sólidos na Região Metropolitana de São Paulo. São Paulo em Perspectiva. 20, 2:90-104, 2006.

JURAS, I. A. G. M. Legislação sobre resíduos sólidos: comparação da lei 12.305/10 com a legislação de países desenvolvidos. Biblioteca Digital da Câmara dos Deputados. Brasília, 2012.

KADAFA, A. A. Solid Waste Management Practice of Residents in Abuja Municipalities (Nigeria). IORS Journal of Environmental Science, Toxicology and Food Technology (JESTFT). 11, 2:87-106, 2017.

LEAL, A. C., THOMAZ, A., GONÇALVES, M. A. A reinserção do lixo na sociedade do capital: uma contribuição ao entendimento do trabalho na catação e na reciclagem.Terra Livre. São Paulo, 2, 19, 2015.

LIRA, E. B.S., NORONHA, C. R. B, ROLIM, F. C., COSTA, A. R. S. Legal aspects of waste disposal in landfills: Aspectos legais da eliminação de resíduos em aterros sanitários no Brasil. Revista Geama. 2, 4:492-501, 2016.

ME - Ministry of the Environment. History and Current State of Waste Management in Japan. 2014. Disponível em (https://www.env.go.jp/en/recycle/smcs/attach/hcswm.pdf). Visualizado em 09/04/2018.

METASUS - European Sustainable Solutions. Expert mission on integrated solid waste management in Bolivia. 2015. Disponível em (https://www.rvo.nl/sites/default/files/2015/06/Bolivia_Report_definitief.pdf). Visualizado em $10 / 09 / 2018$.

MMAa - Ministério do Meio Ambiente. Gestão de Resíduos Orgânicos. Disponível em (http://www.mma.gov.br/cidades-sustentaveis/residuos-solidos/gest\%C3\%A3o-de-res\%C3\%ADduosorg\%C3\%A2nicos). Visualizado em 09/04/2018.

MMAb - Ministério do Meio Ambiente. Coleta Seletiva. Disponível em (http://www.mma.gov.br/cidadessustentaveis/residuos-solidos/catadores-de-materiais-reciclaveis/reciclagem-e-reaproveitamento). Visualizado em $14 / 08 / 2018$. 


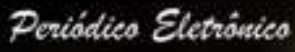 Fórum Ambiental

NALINI, J. E. Mercado de Reciclagem do Lixo no Brasil: Entraves ao Desenvolvimento. São Paulo, 2008. 120 p. Dissertação (Mestrado em Economia Política) - Programa de estudos de Pós-Graduação em Economia Política PUC, Pontifícia Universidade Católica de São Paulo, 2008.

PASCHOALIN, J. A.; SILVEIRA, F. F.; LUZ, E. G.; OLIVEIRA, R. B. Comparação entre as massas de resíduos sólidos urbanos coletadas na cidade de São Paulo por meio de coleta seletiva e domiciliar. Revista de Gestão Ambiental e Sustentabilidade - GeAS. 3, 3:19-33, 2014.

PMSP - Prefeitura do Município de São Paulo. Plano de Gestão Integrada de Resíduos Sólidos. 2014. Disponível em (http://www.prefeitura.sp.gov.br/cidade/secretarias/upload/servicos/arquivos/PGIRS-2014.pdf). Visualizado em 16/04/2018.

PPSP - Portal da Prefeitura de São Paulo. Aterros sanitários e transbordos. 2018. Disponível em (https://www.prefeitura.sp.gov.br/cidade/secretarias/subprefeituras/amlurb/aterros_e_transbordos/index.php?p= 4633). Visualizado em 14/09/2018

PPSP - Portal da Prefeitura de São Paulo. Prefeitura quadriplica porcentagem de reciclagem na cidade. 2016. Disponível em (http://www.capital.sp.gov.br/noticia/prefeitura-quadruplica-porcentagem-de-reciclagem-nacidade). Visualizado em 10/03/2018.

PPSP - Portal da Prefeitura de São Paulo. Resíduos Sólidos. 2009. Disponível em

(http://www.prefeitura.sp.gov.br/cidade/secretarias/inovacao/residuos_solidos/). Visualizado em 09/04/2018.

REIS, M. F.; CONTI, D.; CORRÊA, R. M. Solid Waste Management: Challenges and Opportunities for the City of Sao Paulo. JournalonInnovationandSustainability. RISUS ISSN 2179-3565. 6, 3:77-96, 2015.

RUBERG, C.; AGUIAR, A; PHILIPPI JR, A. Promoção da qualidade ambiental através da reciclagem de resíduos sólidos domiciliares. In: II Simpósio Internacional de Qualidade Ambiental: gerenciamento de resíduos e certificação ambiental, 2, Porto Alegre, 2000. Anais do II SIMPÓsIO INTERNACIONAL DE QUALIDADE AMBIENTAL: GERENCIAMENTO DE RESídUOS E CERTIFICAÇÃO AMBIENTAL. Porto Alegre: Edipucrs, p. 157-170, 2000.

SILVA, A. R. S.; MELO, D. G.; MORAES, F. J. S.; ANTÔNIO, T.; COELHO, T. P. M.; SILVA, G. S. Impactos ambientais referentes à não coleta de lixo e reciclagem. Cadernos de graduação: ciências exatas e tecnológicas. 2, 3:63-76, 2015.

SOUZA, M. C. B. M; MELLO, I. S. Resíduos sólidos: coleta seletiva estímulo para o aumento da reciclagem e melhoria de renda dos catadores. Revista Eletrônica de Gestão \& Saúde. 3, 6:2959-2981, 2015.

SPU - Seattle Public Utilities. 2016 Recycling Rate Report. 2017. Disponível em (https://www.seattle.gov/Util/cs/groups/public/@spu/@garbage/documents/webcontent/1_064754.pdf). Visualizado em 13/09/2018.

TEIXEIRA, E. N.; BIDONE, F. R. A. Metodologias e técnicas de minimização, reciclagem e reutilização de resíduos sólidos urbanos. 1aed., Rio de Janeiro: PROSAB/ABES, 1999. 65 p.

TEODÓSIO, A. S. S.; DIAS, S. F. L. G.; SANTOS, M. C. L. Procrastinação da política nacional de resíduos sólidos: catadores, governos e empresas na governança urbana. Ciência e Cultura. 68, 4:30-33, 2016.

TEPSC - Tokyo Environmental Public Service Corporation. 3Rs and Waste Management in Tokyo. Disponível em (https://www.tokyokankyo.jp/tokyoprogram/en/recycling-technologies/incineration-facilities/). Visualizado em 28/04/2018

WALDMAN, M. Reciclagem, preservação ambiental e o papel dos catadores no Brasil. 2015. Disponível em (http://mw.pro.br/mw/residuos_solidos_07.pdf). Visualizado em 12/09/2018 